\title{
Self-lubricating, wear resistant protic ionic liquid-epoxy resin
}

\author{
M. D. Avilés, N. Saurín, T. Espinosa, J. Sanes, J. Arias-Pardilla, F. J. Carrión, M. D. Bermúdez* \\ Grupo de Ciencia de Materiales e Ingeniería Metalúrgica. Departamento de Ingeniería de Materiales y Fabricación. \\ Universidad Politécnica de Cartagena. Campus de la Muralla del Mar. C/ Doctor Fleming s/n. 30202-Cartagena, Spain
}

Received 30 August 2016; accepted in revised form 8 November 2016

\begin{abstract}
A new self-lubricating, wear resistant epoxy resin material (ER+DCi) has been obtained by addition of a $9 \mathrm{wt} \%$ of the room-temperature protic ionic liquid (PIL) tri-[bis(2-hydroxyethyl)ammonium)] citrate (DCi) to the mixture of the prepolymer and the hardener composed of a mixture of amines. The highly polar tricationic protic ammonium carboxylate ionic liquid shows a high contact angle on the resin surface and distributes inside the epoxy matrix as spheres of around $50 \mu \mathrm{m}$ in diameter, with a mean density of approximately $38 \mathrm{~mm}^{2}$. The presence of the ionic liquid fluid phase inside the cavities has been determined by scanning electron microscopy (SEM) observation of fracture surfaces and Fourier transform infrared spectroscopy (FTIR)-microscopy. The DCi phase reduces the residual curing enthalpy and the glass transition temperature, as determined by DSC, without significantly changing microhardness or electrical resistivity values. Dynamic mechanical analysis (DMA) shows that DCi reduces storage modulus, loss modulus and $\tan \delta$ values. The tribological performance of the new material has been compared with that of the neat epoxy resin under pin-on-disc sliding conditions. ER $+\mathrm{DCi}$ shows more than $50 \%$ reduction of the friction coefficient with respect to neat epoxy resin, and a polished surface, in contrast with the severe wear that takes place in the case of neat epoxy resin. A self-lubrication mechanism by release of the ionic liquid lubricant under load is proposed.
\end{abstract}

Keywords: thermosetting resins, protic ionic liquid, self-lubrication, friction, surface analysis

\section{Introduction}

The development of new polymer nanocomposites for tribological applications [1-10] is one of the fields of research in materials science and technology which has attracted more interest during the last years. Room-temperature ionic liquids (ILs) [11, 12] contain bulk organic cations and organic or inorganic anions and show a unique combination of properties such as their low volatility, non-flammability, and their high thermal stability which are most relevant for tribological applications.

ILs have shown excellent tribological performance, not only in lubrication of metal alloys and ceramic materials under severe sliding conditions [13-25], but also in the very difficult task of achieving the reduction of friction coefficients and wear rates of thermoplastic polymers and epoxy resins, where they have been used both as external lubricants and as additives [26-40].

Ionic liquids are also making an increasing impact in the field of polymer science, in particular on the development of new epoxy networks and composite materials by acting as curing agents, plasticizers, and as dispersants of nanophases in the epoxy matrix [35-39].

We have very recently shown the good tribological performance and the self-healing behaviour of epoxy resin modified by the addition of high percentages (up to $12 \mathrm{wt} \%$ ) of an aprotic ionic liquid [39], or by addition of low concentrations of graphene or graphene modified by ionic liquid [36, 38]. Higher percentages of added aprotic ionic liquid have been shown to transform the brittle epoxy resin into a ductile material $[33,34]$. 
Conventional aprotic ionic liquids with anions that contain halogen atoms present a major drawback due to the possible evolution of potentially hazardous halide-containing small molecules. Several research groups are currently working in the study of halogen-free ILs which could substitute the conventional ones [30, 41, 42].

We have recently developed new lubricants and additives based on protic ionic liquids (PILs), in particular protic ammonium carboxylate salts, some of which show outstanding lubricating behaviour [25, 41-43].

The main objective of the present study is to develop new epoxy resin protic ionic liquid hybrid materials in a simple way, and to determine the effect of the additive on the properties and tribological performance of the polymer, in particular, to prevent the severe surface damage and high friction coefficients of brittle epoxy resin materials. To the best of our knowledge this is the first attempt to develop new materials by addition of a PIL to a polymer matrix.

\section{Experimental}

PIL tri-[bis(2-hydroxyethyl)ammonium)] citrate (DCi) (Figure 1) (viscosity $2.74 \mathrm{~Pa} \cdot \mathrm{s}$ at $25^{\circ} \mathrm{C}$; conductivity $2.7 \cdot 10^{-3} \mathrm{mS} \cdot \mathrm{m}^{-1}$; degradation temperature (50\% weight loss) $234^{\circ} \mathrm{C}$ ) was synthesized from citric acid and diethanolamine [43-45], and kindly provided by Dr. M. Iglesias (Federal University of Bahia, Brazil) and used as received.

Viscosity measurements were made using an AR-G2 rheometer (TA Instruments). Conductivity was measured with a cond600 (Eutech Instruments).

The prepolymer diglycidylether of bisphenol A (DGEBA) (molecular weight $<700$ ) and hardener (mix of amines: 2-piperazin-1-ylethylamine; 3,6-diazooctane-1,8-diaminetriethylenetetramine; 3,6dioxaoctamethylenediamine and 3-aminomethyl3,5,5-trimethylcyclohexylamine) products were obtained from JEMG Gazechim Composites Iberica (Spain).

To obtain the new ER+DCi, the PIL additive was mechanically mixed with the prepolymer by means of an IKA T25 Digital Ultra-Turraxa (Spain) at 16000 rpm
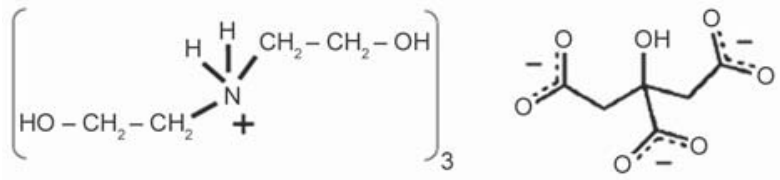

Figure 1. Chemical formula of DCi during 30 seconds. After adding the hardener (28 wt $\%$ ), the mixture was stirred at $1000 \mathrm{rpm}$ for 1 minute under vacuum. Epoxy resin and epoxy resin $+\mathrm{DCi}$ were cured in a vacuum oven at $60^{\circ} \mathrm{C}$ for 2 hours, followed by a 24 hours post-curing step at room temperature. Microscopy FTIR spectra were recorded using a Bruker Vertex 70/70v spectrophotometer couple to an optical microscope (Olympus SD3045). Thermal analysis were carried out using a DSC 822e (Mettler Toledo), under a $\mathrm{N}_{2}$ flow $(50 \mathrm{~mL} / \mathrm{min})$ at a heating rate of $10^{\circ} \mathrm{C} / \mathrm{min}$. Thermogravimetric measurements were performed with a TGA 1HT (Mettler Toledo) equipment $\left(\mathrm{N}_{2}\right.$ flow $50 \mathrm{~mL} / \mathrm{min}$; heating rate of $10^{\circ} \mathrm{C} / \mathrm{min}$ ), in the temperature range from room temperature to $800^{\circ} \mathrm{C}$. A dynamic-mechanical analyzer (DMA) Q800 from TA Instruments was used to determine the viscoelastic properties of the materials, using $30 \times 7.0 \times 3.5 \mathrm{~mm}$ test coupons under the single cantilever configuration, at a heating rate of $3{ }^{\circ} \mathrm{C} / \mathrm{min}$ with a frequency of $1 \mathrm{~Hz}$. Vickers hardness values were determined with a FM310 microhardness tester (Future-Tech, Japan). Shore D hardness values were determined with a TH210 hardness tester.

Sliding tests in a pin-on-disc tribometer (ISC200PC, USA) were carried out using epoxy flat square specimens ( $30 \times 30 \mathrm{~mm} ; 3.5 \mathrm{~mm}$ thickness; roughness $R_{\mathrm{a}}<$ $0.5 \mu \mathrm{m}$ ) and AISI $316 \mathrm{~L}$ steel (hardness $210 \mathrm{HV}$ ) pins ( $0.8 \mathrm{~mm}$ sphere radius) under a normal load of $0.49 \mathrm{~N}$ (contact pressure $0.07 \mathrm{GPa}$ ) and a sliding speed of $0.10 \mathrm{~ms}^{-1}$. The sliding distance was $500 \mathrm{~m}$ and the sliding radius was $9 \mathrm{~mm}$. Wear volumes were measured with a Talysurf CLI 500 (Taylor Hobson) optical profiler. SEM images were obtained using a Hitachi S3500N. The samples were platinum-coated with a SC7640 Sputter Coater before observation. X-ray Photoelectron Spectroscopy (XPS) surface analyses were obtained using an ESCA 5701 (Physical Electronics), taking the adventitious carbon $\mathrm{C}$ $1 \mathrm{~s}$ peak $(285 \mathrm{eV})$ as reference and with an accuracy of $0.2 \mathrm{eV}$. CASAXPS software (v.2.3.15, Casa Software Ltd., Wilmslow, Cheshire, U.K.) [46] was used to fit peaks with close binding energies. The surface was cleaned with ethanol and dried in air before XPS analysis.

\section{Results and discussion}

\subsection{Study of the curing process by DSC}

DSC curves in Figure 2 show the evolution of the curing process with time, comparing the previously described [47] neat epoxy resin, cured with the 

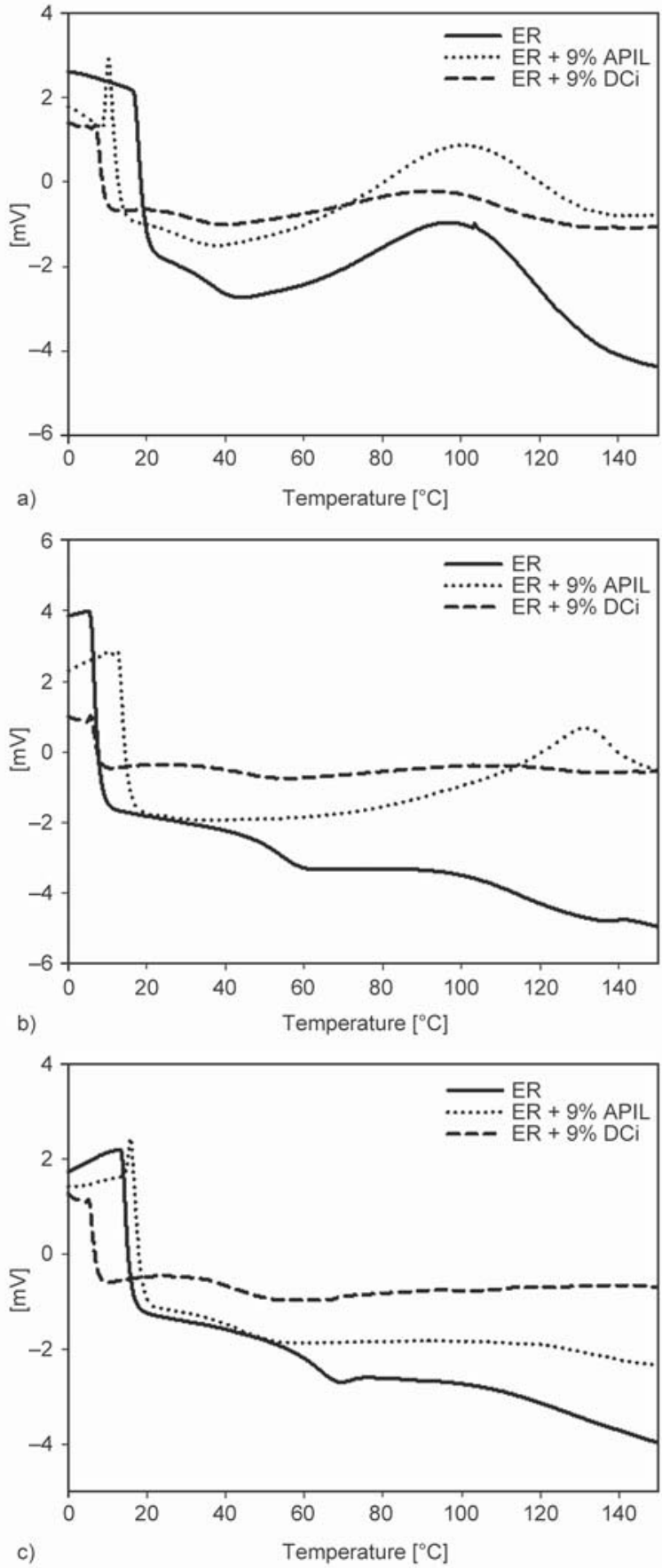

Figure 2. DSC curves as a function of curing time at $60^{\circ} \mathrm{C}$ : a) 20 minutes, b) 40 minutes; c) 60 minutes

Table 1. Residual curing enthalpies

\begin{tabular}{|l|r|c|c|}
\hline \multirow{2}{*}{$\begin{array}{c}\text { Curing time } \\
\left(\mathbf{6 0}^{\circ} \mathbf{C}\right)\end{array}$} & \multicolumn{3}{|c|}{$\begin{array}{c}\Delta \boldsymbol{H} \\
{[\mathbf{J} / \mathbf{g}]}\end{array}$} \\
\cline { 2 - 4 } & $\mathbf{E R}$ & $\mathbf{E R + 9 \% A P I L}$ & $\mathbf{E R + 9 \% D C i}$ \\
\hline $20 \mathrm{~min}$ & 56.7 & 31.4 & 20.8 \\
\hline $40 \mathrm{~min}$ & 9.3 & 16.8 & 6.8 \\
\hline $60 \mathrm{~min}$ & 8.5 & 5.5 & 0.9 \\
\hline
\end{tabular}

mixed amine hardener and $9 \mathrm{wt} \%$ of aprotic imidazolium ionic liquid (APIL), with the epoxy resin cured with the same mixed amine hardener and the protic ammonium citrate (DCi) PIL, in the same
$9 \mathrm{wt} \%$ proportion. Residual curing enthalpy values obtained by integration of the corresponding curves are shown in Table 1.

Although both PIL and APIL ionic liquids act as hardening agents, the new PIL DCi is more efficient from the early stage to the final almost complete curing after 60 minutes, with a $0.9 \mathrm{~J} / \mathrm{g}$ residual enthalpy.

The results show an acceleration of the curing process when the PIL is present, and could be interpreted in terms of the ionic interactions between the PIL molecules and the polar groups present in the polymer chains.

\subsection{Study of PIL distribution in the epoxy matrix.}

Figure 3a shows a SEM micrograph of the fracture surface of ER+DCi, showing the presence of spherical droplets distributed inside the epoxy matrix. Although EDX is not a quantitative technique, element maps (Figure 3b) show the carbon-rich epoxy matrix and the presence of oxygen and nitrogen in the micro-spheres, in agreement with the presence of the ionic liquid PIL phase droplets.

Figure 4 shows the FTIR spectra of the matrix and the fluid phase in a cross section of the ER+DCi material. The presence of the protic ionic liquid is confirmed by the superposition of its FTIR spectrum with that of neat DCi.

In order to quantify the distribution of the PIL in the new ER+DCi material, optical profilometry was used. Figure 5 shows a 3D profile of ER+DCi showing the distribution of DCi within the epoxy matrix, as seen in Figures 3 and 4.

Profilometry measurements have allowed to determine the number and the average size of the microspheres. An average number of 38 microspheres $/ \mathrm{mm}^{2}$, with a mean diameter of $53( \pm 8) \mu \mathrm{m}$ was found.

These results show the influence of ionic liquid composition and polarity on the miscibility with the epoxy matrix, when compared with previously described epoxy resin+APIL materials. Thus, while the shortalkyl chain 1-ethyl-3-methylimidazolium tetrafluoroborate concentrated in small $(2-3 \mu \mathrm{m}$ mean diameter) cavities [30], the less polar, longer-alkyl chain 1-octyl-3-methylimidazolium tetrafluoroborate APIL was miscible with the epoxy matrix, showing a homogeneous distribution within it $[33,39,43]$. The PIL tricationic tricarboxylate $\mathrm{DCi}$, presents a higher polarity than any of the imidazolium APILs, thus it could be concluded that the more polar is the ionic 


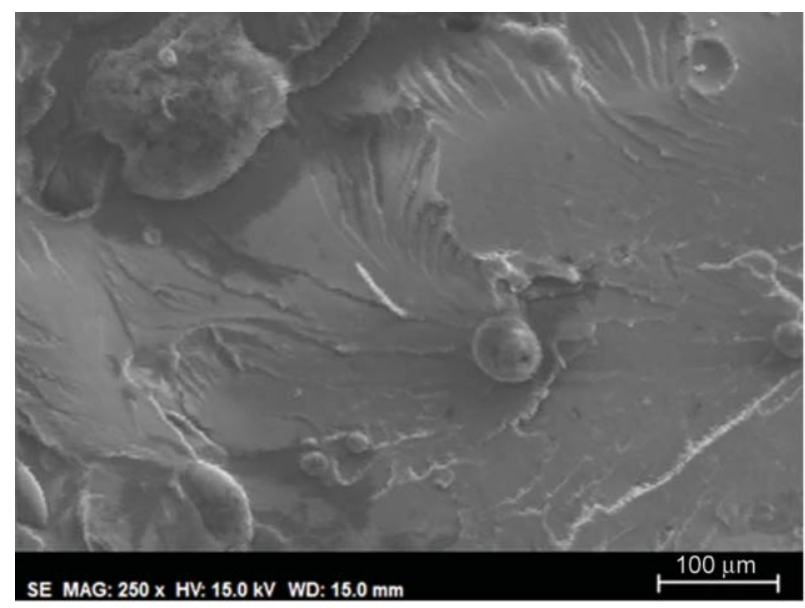

a)

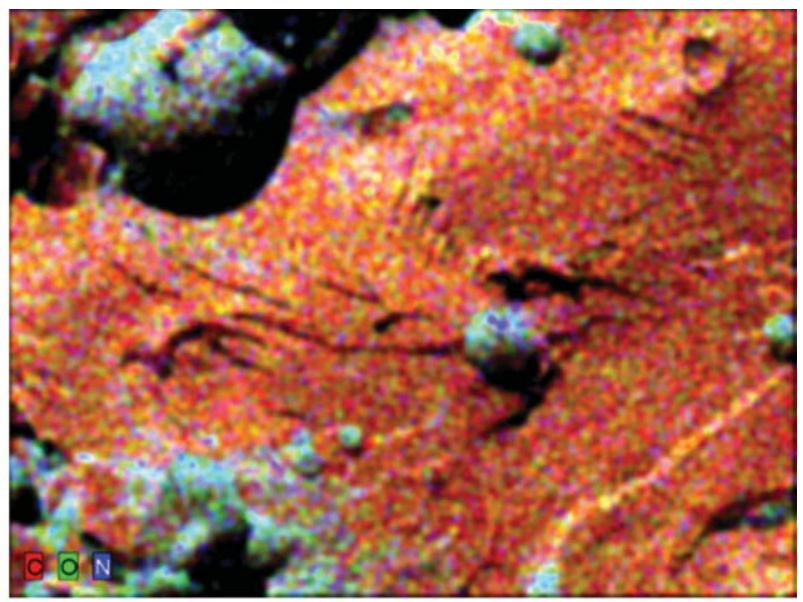

Figure 3. a) SEM micrograph of the fracture surface of ER+DCi; b) EDX element map

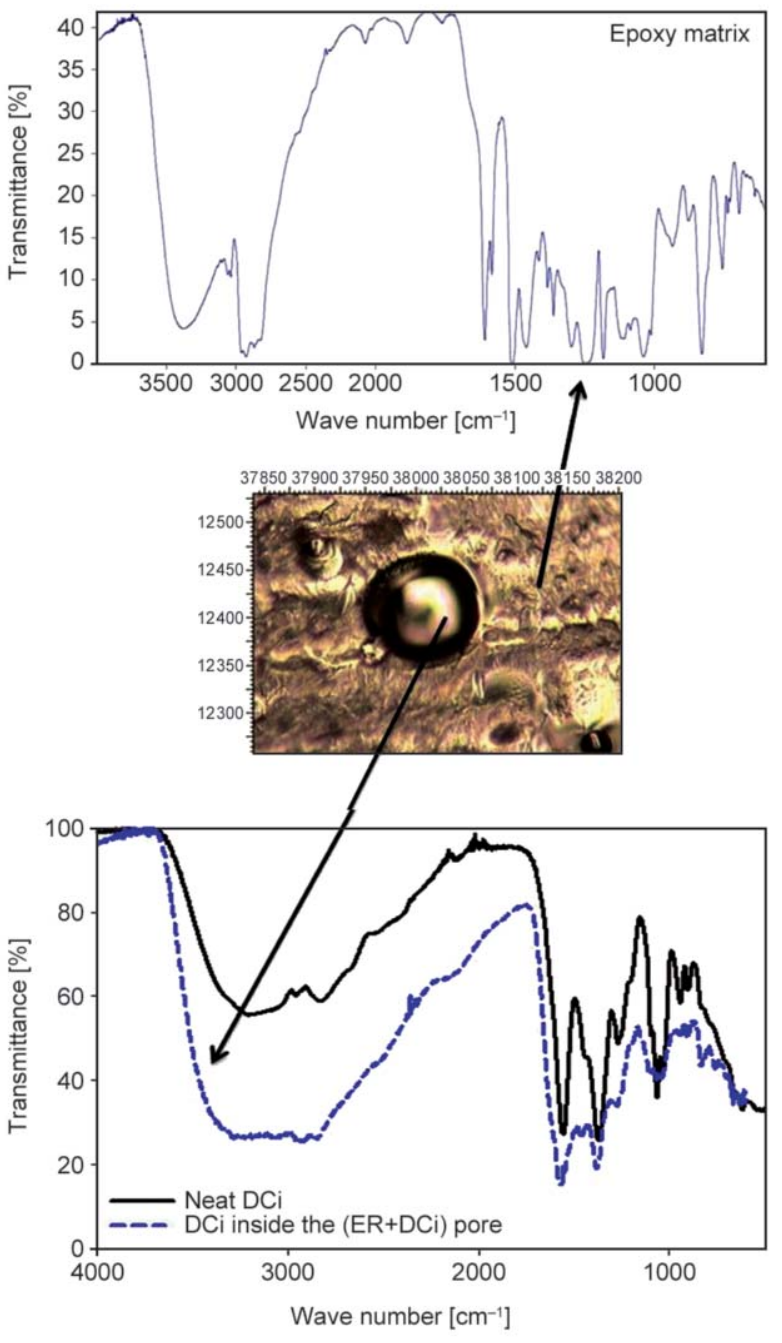

Figure 4. Optical micrograph and FTIR spectra of the epoxy matrix and the DCi PIL phase

Table 2. Thermal properties and hardness values

\begin{tabular}{|c|c|c|c|c|}
\hline \multirow[b]{2}{*}{ Material } & \multirow[b]{2}{*}{$\begin{array}{c}T_{\mathrm{g}}(\mathrm{DSC}) \\
{\left[{ }^{\circ} \mathrm{C}\right]}\end{array}$} & \multirow{2}{*}{$\begin{array}{c}T_{\mathrm{d}}(50 \% \text { weight } \\
\text { loss) (TGA) } \\
{\left[{ }^{\circ} \mathrm{C}\right]}\end{array}$} & \multicolumn{2}{|c|}{ Hardness } \\
\hline & & & $\begin{array}{l}\text { Vickers } \\
\text { (HV) }\end{array}$ & Shore D \\
\hline ER & 91.9 & 343.9 & $20.4( \pm 0.97)$ & $82.9( \pm 0.3)$ \\
\hline $\mathrm{ER}+\mathrm{DCi}$ & 82.1 & 374.0 & $21.2( \pm 1.15)$ & $77.7( \pm 1.5)$ \\
\hline
\end{tabular}

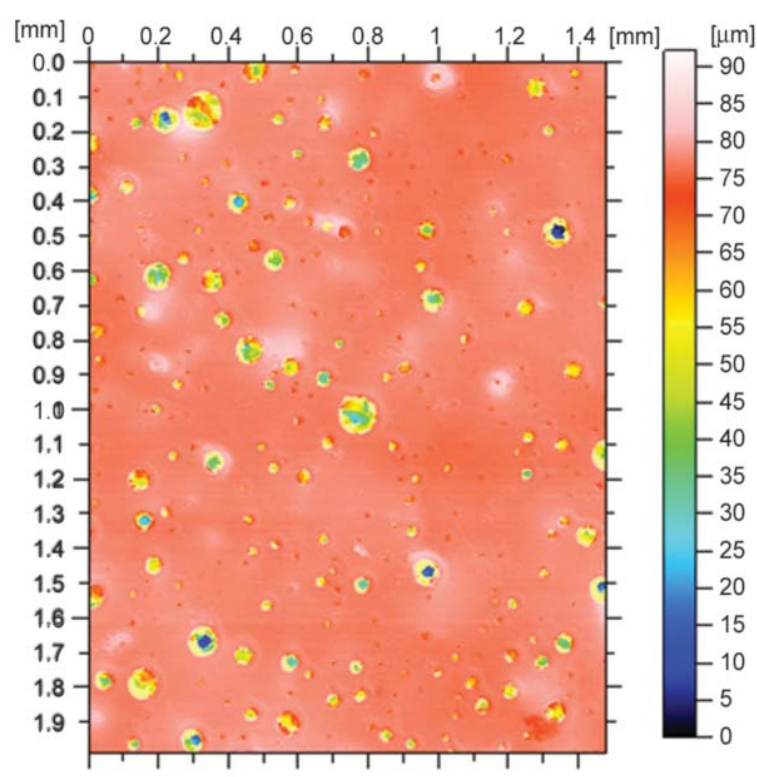

Figure 5. Topographic profile of ER+DCi showing the distribution of $\mathrm{DCi}$

liquid phase, the less miscible with the epoxy matrix, leading to the formation of larger cavities containing the ionic liquid phase.

\subsection{Material properties}

Table 2 shows the results of thermal properties determined by DSC and TGA and hardness values of ER and ER+DCi.

The addition of DCi reduces the glass transition temperature $\left(T_{\mathrm{g}}\right)$ of the epoxy resin in around $10^{\circ} \mathrm{C}$, thus showing the plasticizing effect of the PIL fluid phase which would act as internal lubricant enhancing the chain mobility of the polymer. This is in agreement with previous results obtained for epoxy resin modified by the addition of APILs [29, 38, 47]. However, in this case the reduction in the glass transition tem- 


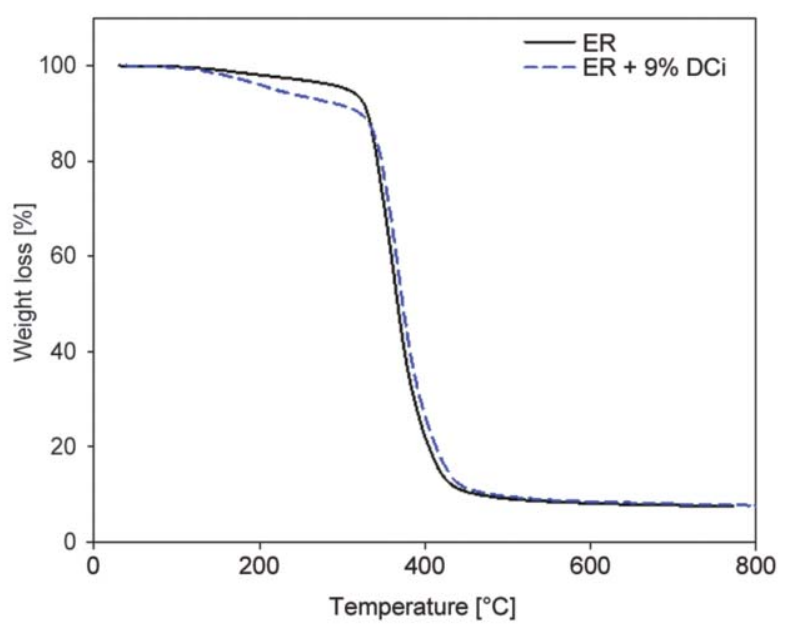

Figure 6. TGA curves for ER and ER+DCi

perature is lower than the $23{ }^{\circ} \mathrm{C}$ reduction observed for ER+9\%APIL (APIL = 1-octyl-3-methylimidazolium tetrafluoroborate) [47]. This difference could be due to the high miscibility of the long alkyl chain substituted imidazolium derivative with the epoxy matrix.

Although, for a $50 \mathrm{wt} \%$ weight loss (Table 2), the degradation temperature of $\mathrm{ER}+\mathrm{DCi}$ is higher than that of ER, the complete thermograms (Figure 6) must be studied in order to understand the thermal stability of both materials.

Figure 6 shows TGA curves for neat ER and for ER+DCi. In the latter case, a first step of a $9.0 \%$ weight loss, up to $310.5^{\circ} \mathrm{C}$, is observed. This result would be in agreement with the loss of the DCi phase, as it is not observed for neat ER.

The hardness value of the epoxy resin (20.4 HV \pm 0.97 ) is not significantly altered by the PIL additive (21.2 \pm 1.15$)$. This result could have anticipated a similar wear resistance of the nanocomposites with respect to the neat epoxy resin.

The addition of a conventional aprotic imidazolium IL to epoxy resin has been shown to generate soft materials with a self-healing ability after abrasion [39, 47].

Table 3 and Figure 7 show the storage modulus $\left(E^{\prime}\right)$ (Figure 7a), loss modulus ( $\left.E^{\prime \prime}\right)$ (Figure 7b) and the loss or dissipation factor, $\tan \delta\left(E^{\prime \prime} / E^{\prime}\right)$ (Figure 7c), determined by dynamic mechanical analysis (DMA). The addition of a $9 \mathrm{wt} \%$ DCi reduces the storage and loss moduli and the $\tan \delta$ values with respect to ER [47], while displacing the maximum $\tan \delta$ temperature to a higher value, from $70.9^{\circ} \mathrm{C}$ for ER [47] to 76.1 for $\mathrm{ER}+\mathrm{DCi}$.
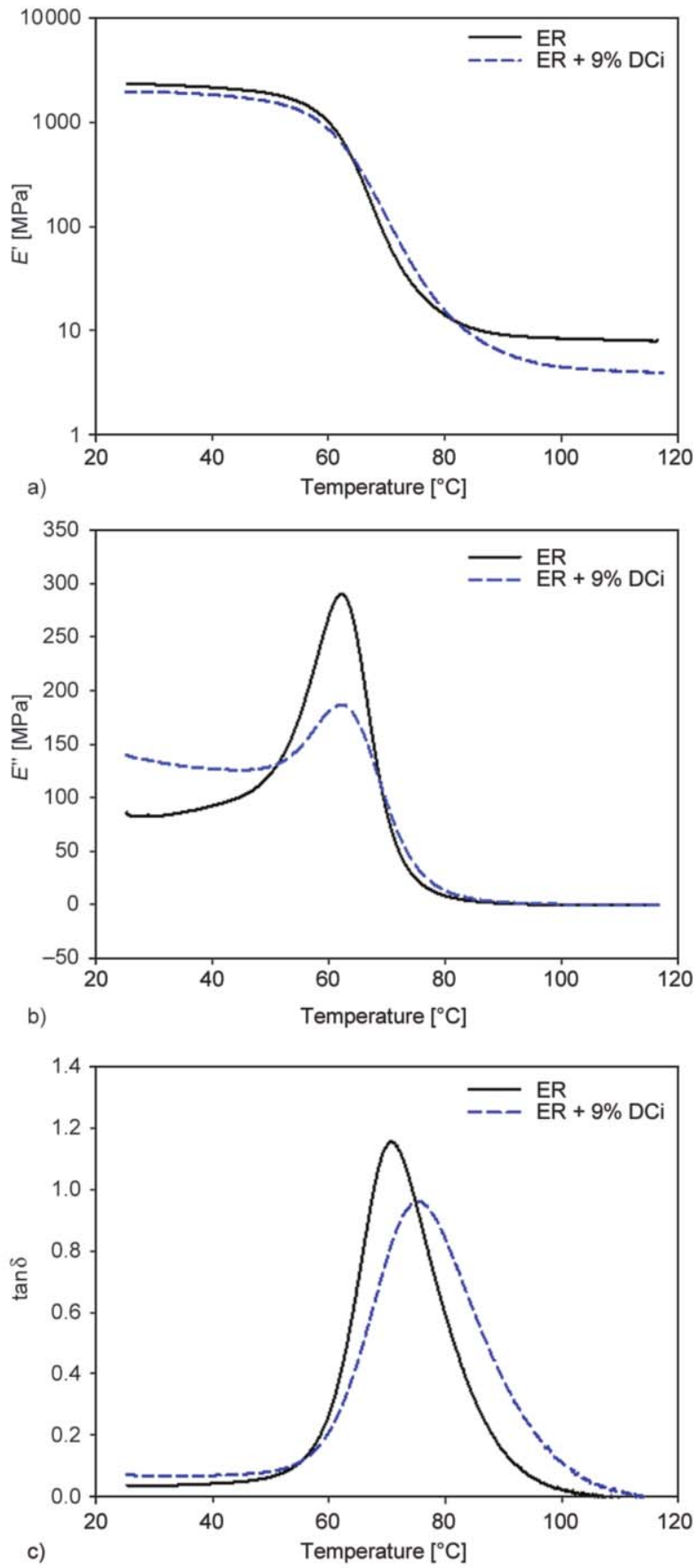

Figure 7. Comparative DMA properties for ER and ER+DCi: a) storage modulus; b) loss modulus; c) $\tan \delta$.

Table 3. Dynamic-mechanical properties

\begin{tabular}{|c|c|c|c|c|c|c|}
\hline Material & $\begin{array}{c}\boldsymbol{E}^{\prime}{ }_{\text {onset }} \\
{[\mathbf{M P a}]}\end{array}$ & $\begin{array}{c}\boldsymbol{T} \\
{\left[{ }^{\circ} \mathbf{C}\right]}\end{array}$ & $\begin{array}{c}\boldsymbol{E}^{\prime \prime}{ }_{\text {maximum }} \\
{[\mathbf{M P a}]}\end{array}$ & $\begin{array}{c}\boldsymbol{T} \\
{\left[{ }^{\circ} \mathbf{C}\right]}\end{array}$ & $\begin{array}{c}\tan \boldsymbol{\delta} \\
\left(\boldsymbol{E}^{\prime \prime} / \boldsymbol{E}^{\prime}\right)\end{array}$ & $\begin{array}{c}\boldsymbol{T} \\
{\left[{ }^{\circ} \mathbf{C}\right]}\end{array}$ \\
\hline $\mathrm{ER}+\mathrm{DCi}$ & 875.0 & 60.4 & 187.6 & 62.5 & 0.97 & 76.1 \\
\hline
\end{tabular}

These results might be interpreted in terms of an increased ductility and crosslink density in ER+DCi. This material also shows a wider $\tan \delta$ peak, which could indicate an increasing degree of inhomogeneity of the spatial distribution of crosslink density. 


\subsection{Tribological behaviour and surface analysis}

The surface of the epoxy resin presents a low wettability in contact with the DCi ionic liquid, as shown by the high contact angle values (Figure 8 ).

This result is in agreement with the low surface interaction and miscibility of the DCi liquid phase with the epoxy matrix.

Figure 9 compares the evolution of friction coefficients with sliding distance for neat epoxy resin (ER) and for the new material (ER+DCi) under dry sliding against AISI 316L (ER/AISI 316L and ER+DCi/ AISI 316L, respectively), and for the ER-AISI 316L contact lubricated with neat DCi added as external lubricant (ER/DCi/AISI 316L).

Up to $100 \mathrm{~m}$, friction coefficients for ER and ER+DCi are very similar, as this initial period corresponds, in both cases, to a contact between the epoxy resin outer skin layer and the steel ball. After $100 \mathrm{~m}$, the friction coefficient for ER starts increasing due to the severe surface damage on neat epoxy resin. ER shows an exponential friction increase with distance, to reach a maximum value of 0.31 after $200 \mathrm{~m}$ (Figure 9) [38]. In contrast, $\mathrm{ER}+\mathrm{DC}$ i shows a very regular friction record, around 0.10 , over the $500 \mathrm{~m}$ sliding distance. The presence of DCi in ER+DCi prevents the friction increase, which shows values between 0.09 and 0.11 after $500 \mathrm{~m}$. The maximum friction coefficient reduction (68\%) takes place after $200 \mathrm{~m}$, with $56 \%$ friction reduction at the end of the test, after $500 \mathrm{~m}$.

Mean friction coefficient values of three tests for the $500 \mathrm{~m}$ sliding distance are $0.15( \pm 0.015)$ for ER and $0.08( \pm 0.008)$ for $\mathrm{ER}+\mathrm{DC}$. These results are even better than those obtained when an imidazolium APIL was used as external lubricant of the epoxy/ stainless steel pair [29], and show an outstanding lubricating performance of the DCi additive. ER $+9 \mathrm{wt} \% \mathrm{APIL}$ (APIL = 1-octyl-3-methylimidazolium tetrafluorob-

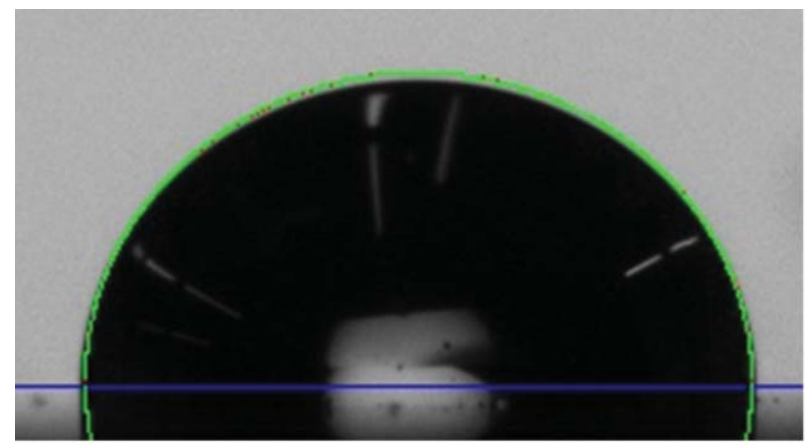

a) orate) only shows a $27 \%$ friction coefficient reduction. Even the addition of graphene (in $0.1 \mathrm{wt} \%$ ) to epoxy resin affords a friction reduction (53\%) [38], which is lower than that found for DCi.

The good lubricating performance of DCi is confirmed when it is used as external lubricant of the neat epoxy/steel contact, with a constant mean friction coefficient value of 0.06 (Figure 9).

Figure 10 shows a SEM micrograph of the ER surface (Figure 10a) and an optical micrograph of the steel ball (Figure 10b) after external lubrication with DCi. The very mild sliding path (arrow in Figure 10a) is similar to surface defects outside the sliding path, while the steel ball (Figure 10b) shows no wear scar. The severe wear presented by the neat epoxy resin, with a wear rate of $8.1 \cdot 10^{-4} \mathrm{~mm}^{3} \cdot \mathrm{Nm}^{-1}$, has been previously described [29].

Figures 11 show the severe wear suffered by the neat epoxy resin under dry conditions, and the wear scar on the AISI 316L steel ball, respectively.

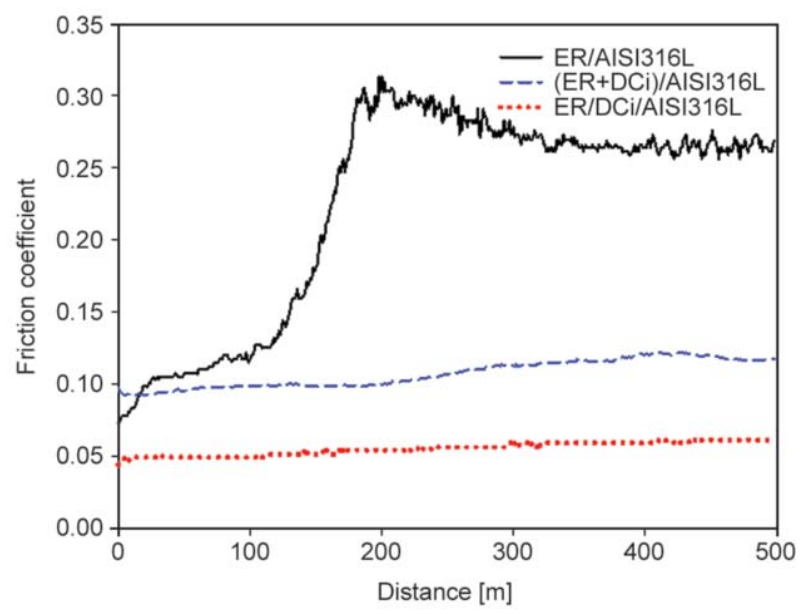

Figure 9. Friction coefficient-sliding distance records for ER/AISI 316L and (ER+DCi)/AISI 316L without added lubricant, and for ER/DCi/AISI 316L, with DCi as added external lubricant

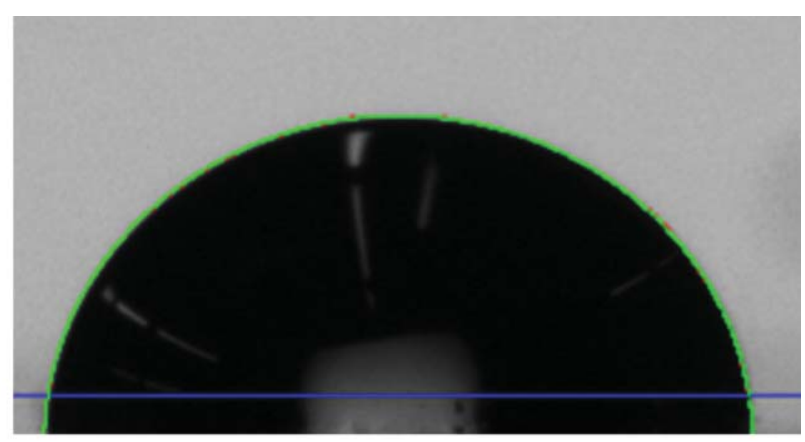

b)

Figure 8. Contact angles of DCi on ER: a) Initial (0 minutes): $91.4^{\circ}( \pm 3.1)$; b) after 5 minutes $79.3^{\circ}( \pm 0.4)$ 


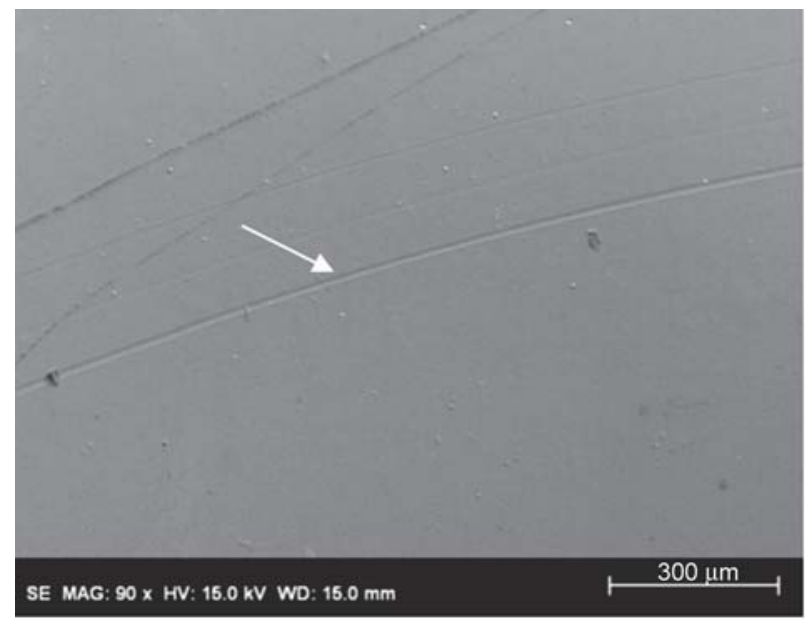

a)

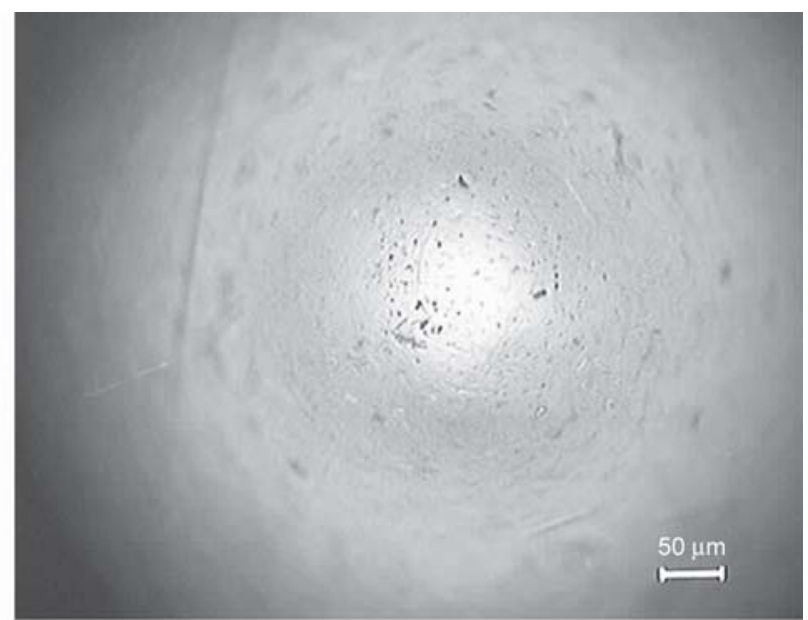

b)

Figure 10. a) SEM micrograph of ER, and b) optical micrograph of steel ball after external lubrication with DCi

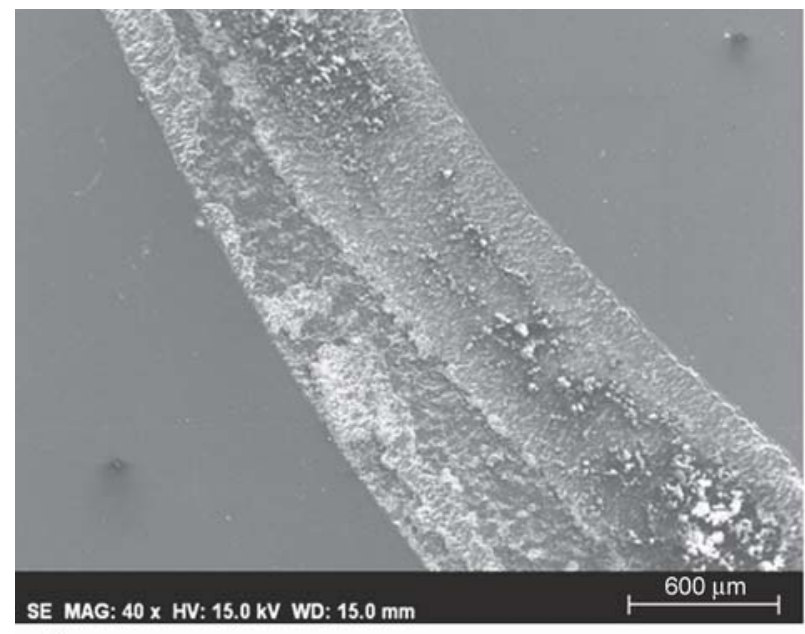

a)

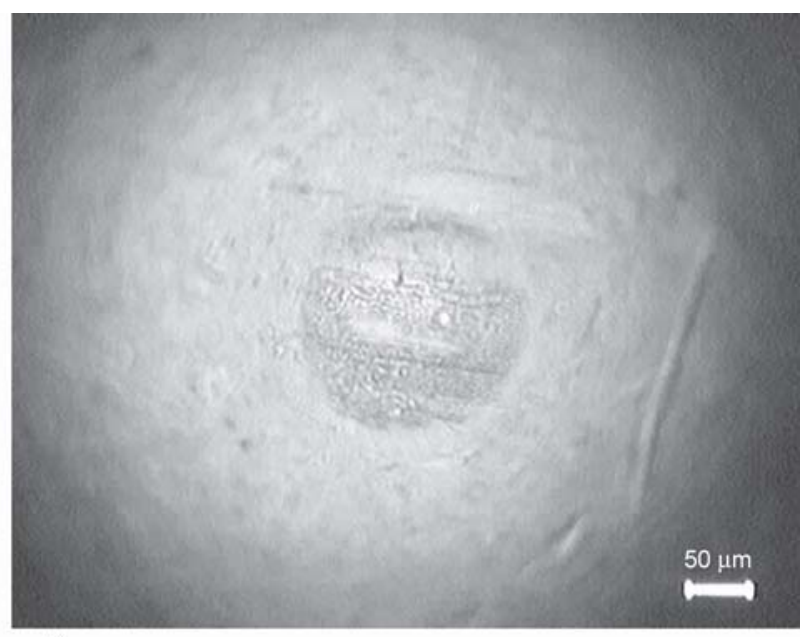

b)

Figure 11. a) SEM micrograph of the wear scar on ER under dry conditions; b) optical micrograph of the AISI 316L steel ball after dry sliding against ER

In contrast, when the region of ER+DCi (Figure 12a) which has supported the load applied by the steel ball is observed by SEM microscopy (Figure 12b), a clean, smooth, polished surface appears (as can be seen in the sliding path regions highlighted between the white dotted lines in Figure 12b).

Remarkably, the only difference which can be appreciated after the sliding of the steel ball is the almost complete absence of surface cavities or pores, with respect to the original surface outside the sliding path (Figure 12a). This would be in agreement with the release of the lubricant fluid phase under load. As can be observed in Figure 12c, the steel surface remains unworn under these conditions.

The low friction coefficient (around 0.10) and absence of measurable wear for the $(\mathrm{ER}+\mathrm{DCi}) / \mathrm{AISI}$ $316 \mathrm{~L}$ pair is maintained for at least $1000 \mathrm{~m}$ of sliding distance, the longest test which has been carried out.
It is important to notice that no segregation of $\mathrm{DCi}$ from the surface of ER+DCi has been observed at room temperature in the absence of applied load. In this way, ER+DCi could be considered a self-lubricating material, where the lubricant is only released when needed.

Recent results have shown the self-lubrication of polymer coatings by the release of conventional fluorinecontaining APILs from microcapsules dispersed in the polymer matrix $[48,49]$, or without microencapsulation [50] in the case of long alkyl chain-substituted imidazolium derivatives, but this is the first time that an halogen-free non-encapsulated ionic liquid is dispersed in an epoxy matrix, showing not only self-lubricating behaviour, but also wear preventing ability.

Surface analysis inside the sliding path presents difficulties in this case, as there is no wear track. However, XPS analysis of an area including the sliding 


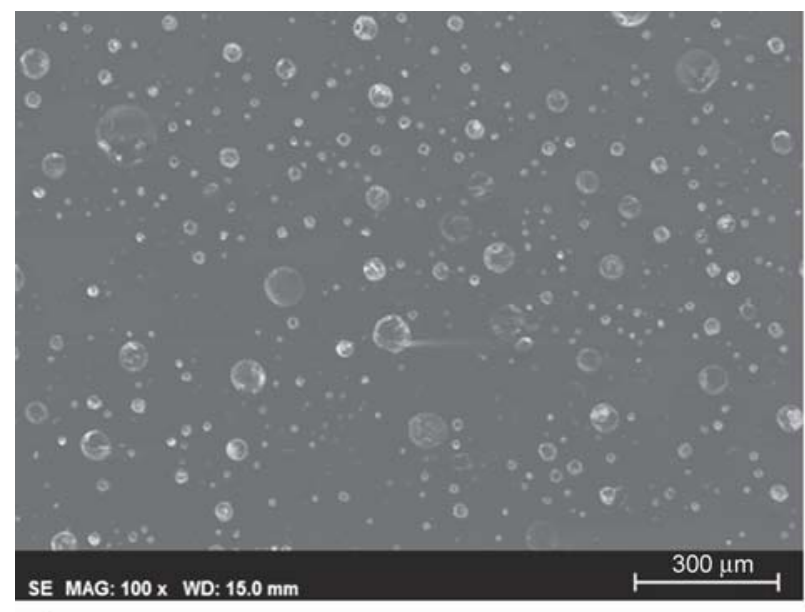

a)

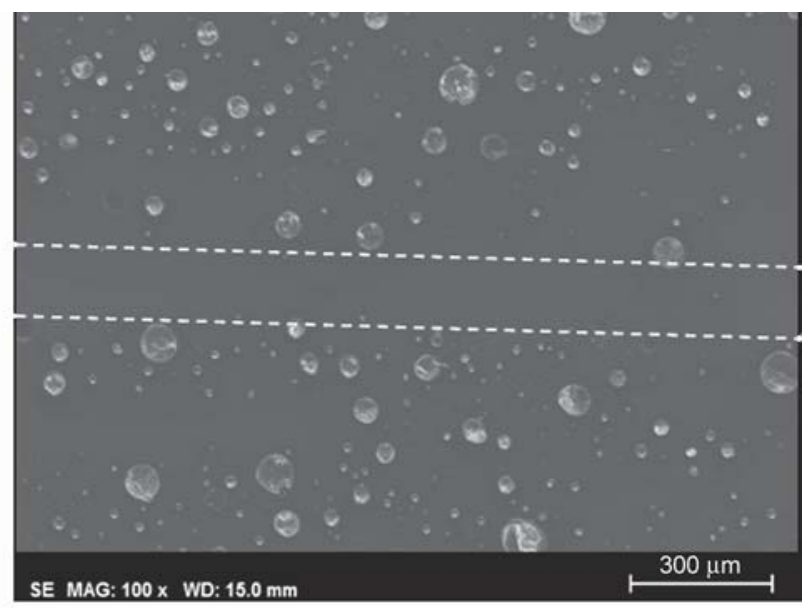

b)

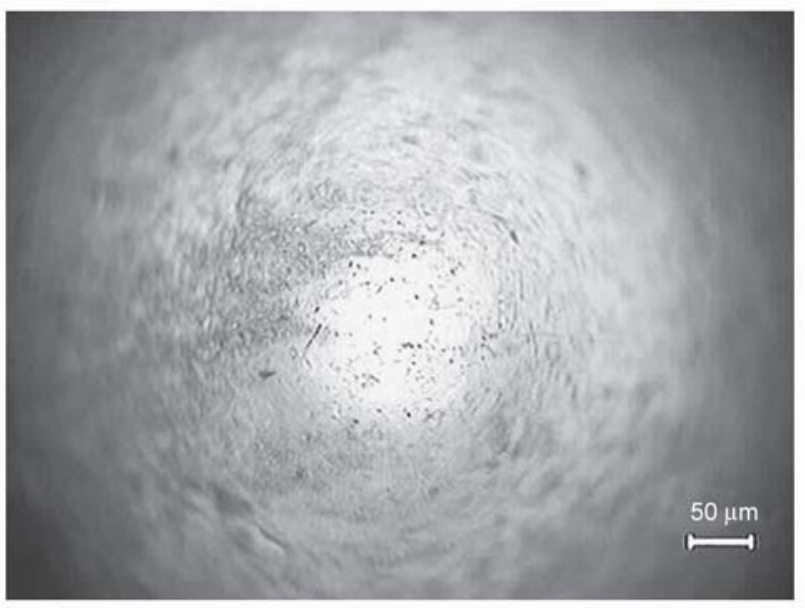

c)

Figure 12. SEM micrographs of ER+DCi: a) before the tribological test; b) after the tribological test. c) optical micrograph of the steel ball after the test against $\mathrm{ER}+\mathrm{DCi}$

path (Figure 13) has been compared with that for neat DCi (Figure 14).

Among the four $\mathrm{C} 1 \mathrm{~s}$ peaks and three N1s peaks appear in both XPS spectra (Figures 13 and 14), the C1s peak at $287.7 \mathrm{eV}$ and the $\mathrm{N} 1 \mathrm{~s}$ peak at $400.8 \mathrm{eV}$ could be specifically assigned, respectively, to $\mathrm{C}-\mathrm{N}, \mathrm{N}-\mathrm{H}$ and $\mathrm{C}-\mathrm{O}$ groups present in $\mathrm{DCi}$, are also observed on the sliding path surface of ER+DCi (Figure 12b).

\section{Conclusions}

A new self-lubricating epoxy resin material modified by the dispersion of a protic ammonium carboxylate ionic liquid in the epoxy matrix has been obtained and characterized. The protic ionic liquid acts as a curing and plasticizing agent, increasing the ductility and crosslinking density. The high polarity of the protic ionic liquid molecules produces low miscibility of the liquid phase within the epoxy matrix and reduces the wettability of the resin surface. Friction coefficients are reduced by the protic ionic liquid, both when used as external added lubricant or as self-lu- bricating agent, when the ionic liquid is released from the epoxy resin under load. In all cases, the presence of the ionic liquid protects the resin surface from the severe wear damage characteristic of neat epoxy resin. At the sliding path, after the release of the protic ionic liquid, the surface cavities which contained it are healed resulting in a polished surface.

\section{Acknowledgements}

The authors wish to thank the financial support of the Ministerio de Economía y Competitividad (MINECO, Spain) and the EU FEDER (MAT2014- 55384-P), and the Fundación Séneca, Agencia de Ciencia y Tecnología de la Región de Murcia for a 'Ayuda a las Unidades y Grupos de Excelencia Científica de la Región de Murcia (Programa Séneca 2014)' (Grant 19877/GERM/14). M.D. Avilés is grateful to the MINECO (Spain) for a research grant (BES-2015-074836). N. Saurín is grateful to MINECO (Spain) for a research grant (BES-2012-056621). T. Espinosa is grateful to Ministerio de Educación (MECD, Spain) for grant AP2010-3485. The authors are grateful to Dr. M. Iglesias (Federal University of Bahia, Brazil) for the synthesis of DCi. 

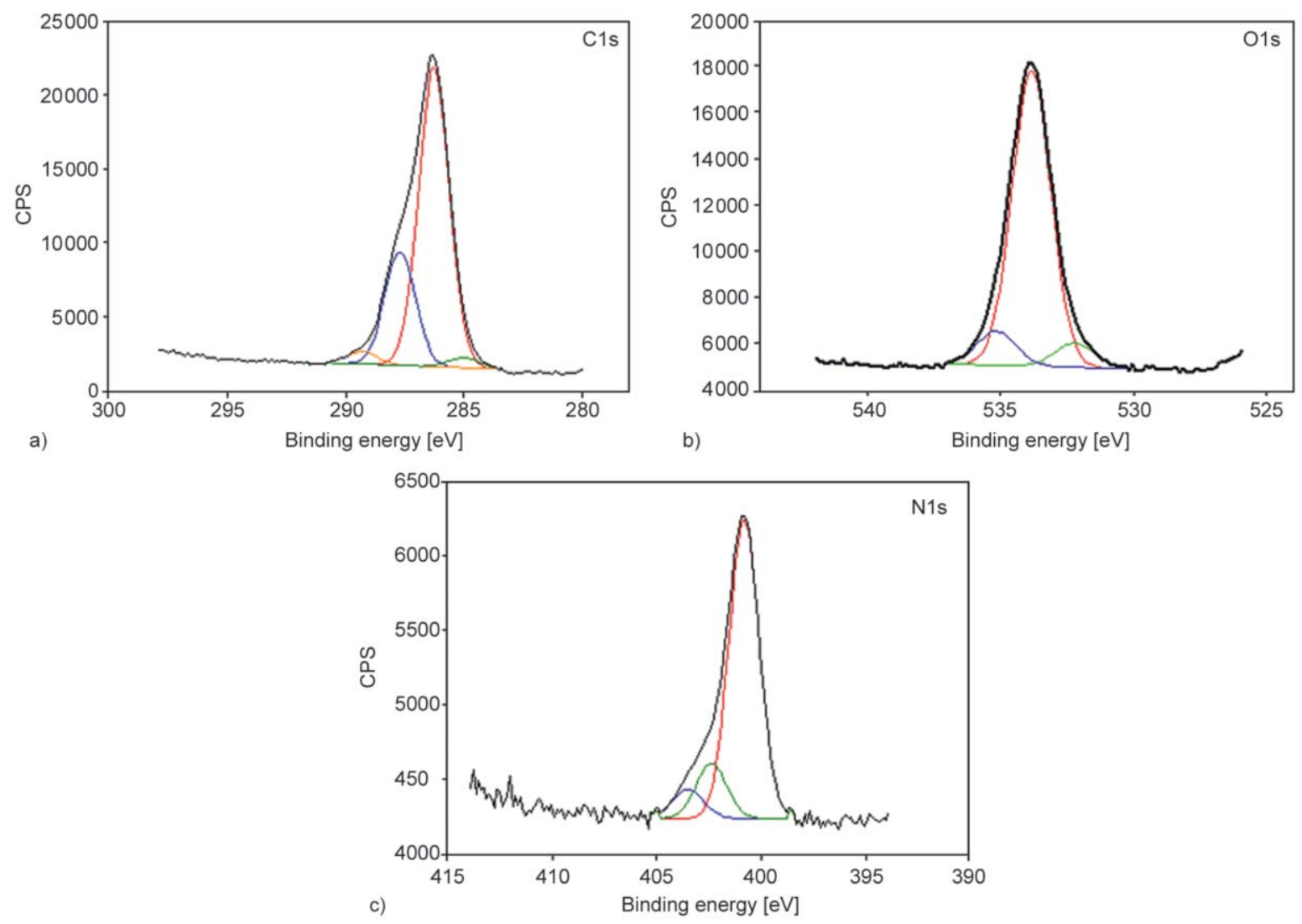

Figure 13. a) C1s, b) O1s and c) N1s XPS spectra of ER+DCi after the tribological test

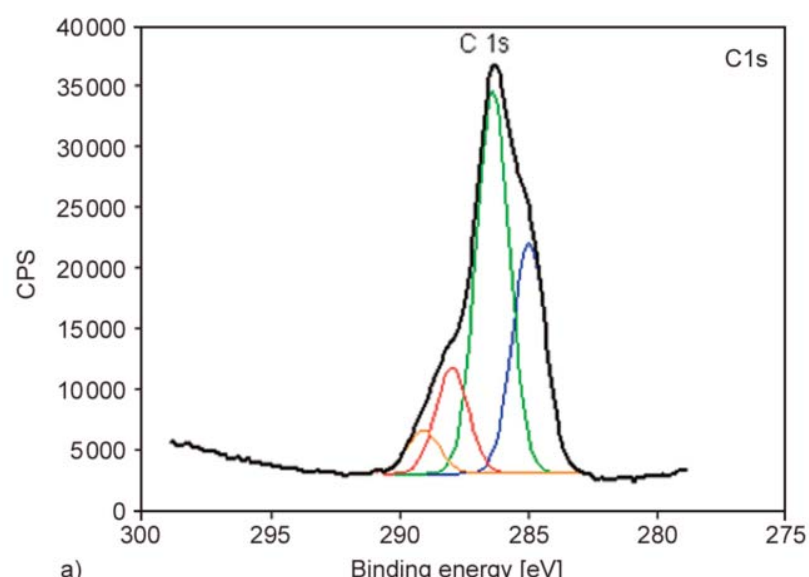

a) Binding energy $[\mathrm{eV}] \quad$ b)
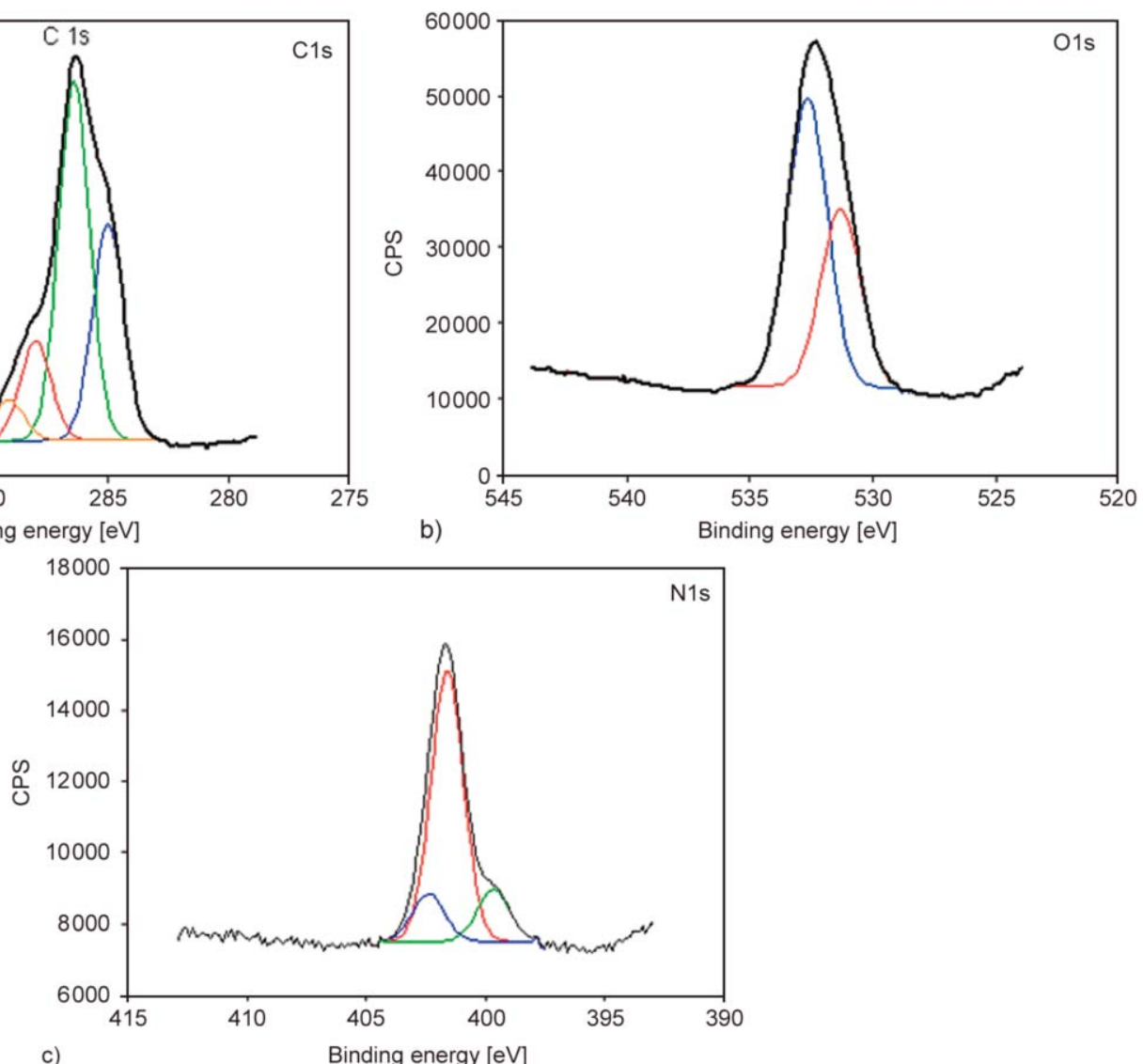

c)

Figure 14. a) $\mathrm{C} 1 \mathrm{~s}$, b) $\mathrm{O} 1 \mathrm{~s}$ and c) N1s XPS spectra of neat DCi 


\section{References}

[1] Duncan T. V.: Release of engineered nanomaterials from polymer nanocomposites: The effect of matrix degradation. ACS Applied Materials and Interfaces, 7, 2039 (2015).

https://doi.org/10.1021/am5062757

[2] Domun N., Hadavinia H., Zhang T., Sainsbury T., Liaghat G. H., Vahid S.: Improving the fracture toughness and the strength of epoxy using nanomaterials - A review of the current status. Nanoscale, 7, 10294 10329 (2015).

https://doi.org/10.1039/C5NR01354B

[3] Burris D. L., Boesl B., Bourne G. R., Sawyer W. G.: Polymeric nanocomposites for tribological applications. Macromolecular Materials and Engineering, 292, 387402 (2007).

https://doi.org/10.1002/mame.200600416

[4] Dasari A., Yu Z-Z., Mai Y-W.: Fundamental aspects and recent progress on wear/scratch damage in polymer nanocomposites. Materials Science and Engineering R, 63, 31-80 (2009).

https://doi.org/10.1016/j.mser.2008.10.001

[5] Brostow W., Kovacevic V., Vrsaljko D., Whitworth J.: Tribology of polymers and polymer based composites. Journal of Materials Education, 32, 273-290 (2010).

[6] Brostow W., Deborde J-L., Jaklevicz M., Olszynski P.: Tribology with emphasis on polymers: Friction, scratch resistance and wear. Journal of Materials Education, 25, 119-132 (2003).

[7] Myshkin N. K., Petrokovets M. I., Kovalev A. V.: Tribology of polymers: Adhesion, friction, wear, and masstransfer. Tribology International, 38, 910-921 (2005). https://doi.org/10.1016/j.triboint.2005.07.016

[8] Brostow W., Simoes R.: Tribological and mechanical behavior of metals and polymers simulated by molecular dynamics. Journal of Materials Education, 27, 19 28 (2005).

[9] Brostow W., Lobland H. E. H., Narkis M.: Sliding wear, viscoelasticity, and brittleness of polymers. Journal of Materials Research, 21, 2422-2428 (2006).

https://doi.org/10.1557/JMR.2006.0300

[10] Brostow W., Dutta M., Rusek P.: Modified epoxy coatings on mild steel: Tribology and surface energy. European Polymer Journal, 46, 2181-2189 (2010). https://doi.org/10.1016/j.eurpolymj.2010.08.006

[11] Wasserscheid P., Welton T.: Ionic liquids in synthesis. Wiley-VCH, Weinheim (2008).

https://doi.org/10.1002/9783527621194

[12] Wilkes J. S., Zaworotko M. J.: Air and water stable 1ethyl-3-methylimidazolium based ionic liquids. Chemical Communications, 1992, 965-967 (1992).

https://doi.org/10.1039/c39920000965

[13] Ye C., Liu W., Chen Y., Yu L.: Room-temperature ionic liquids: A novel versatile lubricant. Chemical Communications, 2001, 2244-2245 (2001).

https://doi.org/10.1039/b106935g
[14] Torimoto T., Tsuda K., Okazaki K-I., Kuwabata S.: New frontiers in materials science opened by ionic liquids. Advanced Materials, 22, 1196-1221 (2010). https://doi.org/10.1002/adma.200902184

[15] Zhang S., Zhang Q., Zhang Y., Chen Z., Watanabe M., Deng Y.: Beyond solvents and electrolytes: Ionic liquids-based advanced functional materials. Progress in Materials Science, 77, 80-124 (2016). https://doi.org/10.1016/j.pmatsci.2015.10.001

[16] Minami I.: Ionic liquids in tribology. Molecules, 14, 2286-2305 (2009). https://doi.org/10.3390/molecules 14062286

[17] Bermúdez M. D., Jiménez A-E., Sanes J., Carrión F-J.: Ionic liquids as advanced lubricant fluids. Molecules, 14, 2888-2908 (2009). https://doi.org/10.3390/molecules 14082888

[18] Van Rensselar J.: Unleashing the potential of ionic liquids. Tribology and Lubrication Technology, 4, 24-31 (2010).

[19] Palacio M., Bushan B. A.: A review of ionic liquids for green molecular lubrication in nanotechnology. Tribology Letters, 40, 247-268 (2010). https://doi.org/10.1007/s11249-010-9671-8

[20] Somers A. E., Howlett P. C., MacFarlane D. R., Forsyth M.: A review of ionic liquid lubricants. Lubricants, 1, 3-21 (2013).

https://doi.org/10.3390/lubricants 1010003

[21] Bermúdez M-D.: Introduction to the ionic liquids special issue. Tribology Letters, 40, 213 (2010). https://doi.org/10.1007/s11249-010-9707-0

[22] Dörr N.: Special issue on ionic liquids as lubricants. Proceedings of the Institution of Mechanical Engineers Part J: Journal of Engineering Tribology, 226, 889-890 (2012). https://doi.org/10.1177/1350650112464332

[23] Angell C. A., Ansari Y., Zhao Z. F.: Ionic Liquids: Past, present and future. Faraday Discussions, 154, 9-27 (2012).

https://doi.org/10.1039/c1fd00112d

[24] Predel T., Pohrer B., Schlücker E.: Ionic liquids as alternative lubricants for special applications. Chemical Engineering and Technology, 33, 132-136 (2010). https://doi.org/10.1002/ceat.200900325

[25] Bermúdez M. D., Carrion F. J., Jimenez A. E., Sanes J., Martínez-Nicolas G., Espejo, C., Espinosa T., Jimenez M., Arias J., Ojados G., Gonzalez N.: Tribological performance and surface interactions of new ionic nanofluids and nanomaterials. in ' $244^{\text {th }}$ ACS National Meeting \& Exposition, Philadelphia, Pennsylvania' 205, 1 (2012).

[26] Sanes J., Carrión F. J., Bermúdez M. D., MartínezNicolás G.: Ionic liquids as lubricants of polystyrene and polyamide 6-steel contacts. Preparation and properties of new polymer-ionic liquid dispersions. Tribology Letters, 21, 121-133 (2006).

https://doi.org/10.1007/s11249-006-9028-5 
[27] Sanes J., Carrión F. J., Jiménez A. E., Bermúdez M. D.: Influence of temperature on PA 6-steel contacts in the presence of an ionic liquid lubricant. Wear, 263, 658662 (2007).

https://doi.org/10.1016/j.wear.2006.11.034

[28] Carrión F. J., Sanes J., Bermúdez M. D.: Effect of ionic liquid on the structure and tribological properties of polycarbonate-zinc oxide nanodispersion. Materials Letters, 61, 4531-4535 (2007).

https://doi.org/10.1016/j.matlet.2007.02.044

[29] Sanes J., Carrion-Vilches F-J., Bermúdez M-D.: New epoxy-ionic liquid dispersions. Room temperature ionic liquid as lubricant of epoxy resin-stainless steel contacts. e-Polymers, no.005 (2007).

https://doi.org/10.1515/epoly.2007.7.1.48

[30] Saurín N., Minami I., Sanes J., Bermúdez M. D.: Study of the effect of tribo-materials and surface finish on the lubricant performance of new halogen-free room temperature ionic liquids. Applied Surface Science, 366, 464-474 (2016).

https://doi.org/10.1016/j.apsusc.2016.01.127

[31] Maka H., Spychaj T., Zenker M.: High performance epoxy composites cured with ionic liquids. Journal of Industrial and Engineering Chemistry, 31, 192-198 (2015). https://doi.org/10.1016/j.jiec.2015.06.023

[32] Nguyen T. K. L., Livi S., Soares B. G., Pruvost S., Duchet-Rumeau J., Gerard J-F.: Ionic liquids: A new route for the design of epoxy networks. ACS Sustainable Chemistry and Engineering, 4, 481-490 (2016). https://doi.org/10.1021/acssuschemeng.5b00953

[33] Hameed N., Salim N. V., Walsh T. R., Wiggins J. S., Ajayan P. M., Fox B. L.: Ductile thermoset polymers via controlling network flexibility. Chemical Communications, 51, 9903-9906 (2015).

https://doi.org/10.1039/c4cc10192h

[34] Hameed N., Bavishi J., Parameswarampillai J., Salim N. V., Joseph J., Madras G., Fox B. L.: Thermally flexible epoxy/cellulose blends mediated by an ionic liquid. RSC Advances, 5, 52832-52836 (2015).

https://doi.org/10.1039/c5ra05900c

[35] Sanes J., Carrión F. J., Bermúdez M. D.: Effect of the addition of room temperature ionic liquid and $\mathrm{ZnO}$ nanoparticles on the wear and scratch resistance of epoxy resin. Wear, 268, 1295-1302 (2010). https://doi.org/10.1016/j.wear.2010.01.024

[36] Saurín N., Sanes J., Bermúdez M. D.: New graphene/ ionic liquid nanolubricants. Materials Today: Proceedings, 3, S227-S232 (2016).

https://doi.org/10.1016/j.matpr.2016.02.038

[37] Saurín N., Espinosa T., Sanes J., Carrion F-J., Bermúdez M-D.: Ionic nanofluids in tribology. Lubricants, 3, 650-663 (2015).

https://doi.org/10.3390/lubricants3040650

[38] Saurín N., Sanes J., Bermúdez M. D.: Effect of graphene and ionic liquid additives on the tribological performance of epoxy resin. Tribology Letters, 56, 133-142 (2014). https://doi.org/10.1007/s11249-014-0392-2
[39] Saurín N., Sanes J., Bermúdez M. D.: Self-healing of abrasion damage in epoxy resin-ionic liquid nanocomposites. Tribology Letters, 58, 4/1-4/9 (2015). https://doi.org/10.1007/s11249-015-0490-9

[40] Mąka H., Spychaj T., Kowalczyk K.: Imidazolium and deep eutectic ionic liquids as epoxy resin crosslinkers and graphite nanoplatelets dispersants. Journal of Applied Polymer Science, 131, 40401/1-40401/7 (2014). https://doi.org/10.1002/app.40401

[41] Espinosa T., Sanes J., Jiménez A. E., Bermúdez M-D.: Protic ammonium carboxylate ionic liquid lubricants of OFHC copper. Wear, 303, 495-509 (2013).

https://doi.org/10.1016/j.wear.2013.03.041

[42] Espinosa T., Sanes J., Jiménez A-E., Bermúdez M-D.: Surface interactions, corrosion processes and lubricating performance of protic and aprotic ionic liquids with OFHC copper. Applied Surface Science, 273, 578-597 (2013). https://doi.org/10.1016/j.apsusc.2013.02.083

[43] Peric B., Martí E., Sierra J., Cruanas R., Iglesias M., Garau M. A.: Terrestrial ecotoxicity of short aliphatic protic ionic liquids. Environmental Toxicology and Chemistry, 30, 2802-2809 (2011). https://doi.org/10.1002/etc.683

[44] Mattedi S., Martin-Pastor M., Iglesias M.: Structural and aggregation study of protic ionic liquids. in 'International congress on advances in applied physics and materials science, Antalya, Turkey' 1400, 154-158 (2011). https://doi.org/10.1063/1.3663104

[45] Iglesias M., Gonzalez-Olmos R., Cota I., Medina F.: Brønsted ionic liquids: Study of physico-chemical properties and catalytic activity in aldol condensations. Chemical Engineering Journal, 162, 802-808 (2010). https://doi.org/10.1016/j.cej.2010.06.008

[46] Moulder J. F., Chastain J.: Handbook of X-ray photoelectron spectroscopy. Perkin Elmer, Eden Prairie (1992).

[47] Saurín N., Sanes J., Carrión F. J., Bermúdez M. D.: Selfhealing of abrasion damage on epoxy resin controlled by ionic liquid. RSC Advances, 6, 37258-37264 (2016). https://doi.org/10.1039/c6ra05503f

[48] Bandeira P., Monteiro J., Baptista A. M., Magalhaes F. D.: Tribological performance of PTFE-based coating modified with microencapsulated [HMIM] $\left.\mathrm{NTf}_{2}\right]$ ionic liquid. Tribology Letters, 59, 13/1-13/15 (2015). https://doi.org/10.1007/s11249-015-0545-y

[49] Yang M., Zhu X., Ren G., Men X., Guo F., Li P., Zhang Z.: Tribological behaviors of polyurethane composite coatings filled with ionic liquid core/silica gel shell microcapsules. Tribology Letters, 58, 9/1-9/9 (2015). https://doi.org/10.1007/s11249-015-0492-7

[50] Bandeira P., Monteiro J., Baptista A. M., Magalhães F. D.: Influence of oxidized graphene nanoplatelets and $[\mathrm{DMIM}]\left[\mathrm{NTf}_{2}\right]$ ionic liquid on the tribological performance of an epoxy-PTFE coating. Tribology International, 97, 478-489 (2016). https://doi.org/10.1016/j.triboint.2016.02.005 